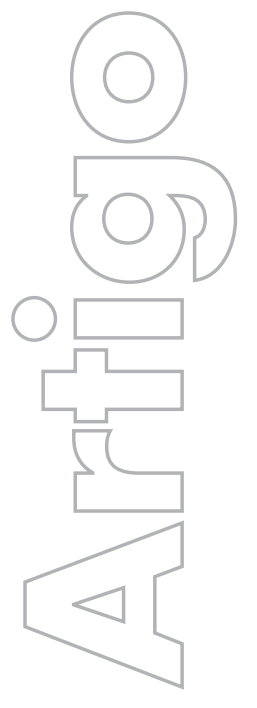

revista

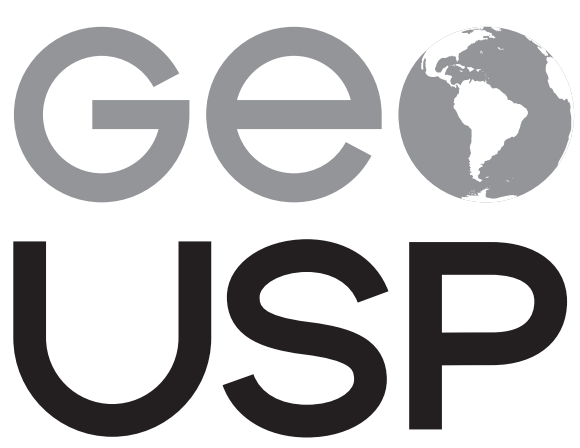

espaço e tempo

Volume $20 \cdot n^{\circ} 3(2016)$
Mudanças na dinâmica fluvial da bacia hidrográfica do ribeirão Araquá: eventos tectônicos e climáticos no Quaternário

\author{
André de Oliveira Souza \\ Unicamp
}

Archimedes Perez Filho

Unicamp

p. $636-656$

Como citar este artigo:

SOUZA, A. AO.; PEREZ FILHO, A. Mudanças na dinâmica fluvial da bacia hidrográfica do ribeirão Araquá: eventos tectônicos e climáticos no Quaternário. Geousp - Espaço e Tempo (Online), v. 20, n. 3, p. 636-656, mês. 2016. ISSN 2179-0892.

Disponível em: <http://www.revistas.usp.br/geousp/issue/ view/6465>. doi: http://dx.doi.org/10.11606/issn.2179-0892. geousp. 2014.84539.

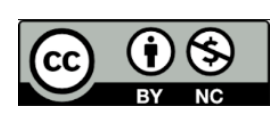

Este artigo está licenciado sob a Creative Commons Attribution 4.0 License. 


\title{
Mudanças na dinâmica fluvial da bacia hidrográfica do ribeirão Araquá: eventos tectônicos e climáticos no Quaternário
}

\section{Resumo}

Este artigo apresenta os resultados dos estudos sobre a dinâmica geomorfológica quaternária da bacia do ribeirão Araquá, nos municípios de São Pedro e Charqueada-SP. $\bigcirc$ trabalho parte do pressuposto de que eventos neotectônicos e climáticos influenciaram a mudança da dinâmica fluvial dessa bacia. Assim, o objetivo principal da pesquisa foi investigar a relação desses eventos com a formação de dois níveis de altos terraços e das linhas de cascalho neles identificadas. Adotaram-se parâmetros flúvio-morfométricos e datação de sedimentos fluviais por luminescência opticamente estimulada (LOE). Os resultados apontaram a coalescência de eventos neotectônicos durante o Pleistoceno Superior e climáticos na transição Pleistoceno Superior-Holoceno como responsáveis pelas alterações no nível de base e na formação dos terraços fluviais.

Palavras-chave: Geomorfologia fluvial. Neotectônica. Terraços fluviais. LOE. Quaternário.

\section{Changes in fluvial dynamics of the Araquá river watershed: tectonic and climate events in the Quaternary}

\begin{abstract}
This paper presents the results of studies concerning the Quaternary geomorphological dynamics of the Araquá River watershed, localized in São Pedro and Charqueada cities in São Paulo State, Brazil. This work assumes that climatic and neotectonic events have influenced the spatial distribution of this river system. Therefore, the aim of this research was to investigate the relationship of neotectonic and climatic events with changes in the river dynamics, which originated the stone-lines of the two high terrace levels of the Araquá river basin. The research was performed through the analysis of morphometric/fluvial parameters and absolute dating of fluvial sediments through Optically Stimulated Luminescence. The results pointed to a coalescence of Pleistocene neotectonic
\end{abstract}


activity and climatic events in the Pleistocene/Holocene transition. These events probably influenced in the formation of the gravel lines and in the development of the two levels of high terraces.

Keywords: Fluvial Geomorphology. Neotectonics. Fluvial terraces. OSL. Quaternary.

\section{Introdução}

A gênese e evolução das formas de relevo estão condicionadas aos diferentes processos naturais e antrópicos que interagem por meio de trocas de energia e matéria, nos moldes de um sistema aberto e complexo. Nesse contexto, destaca-se a importância dos sistemas fluviais e da condição ativo-passivo na elaboração do relevo, isto é, ao mesmo tempo em que são agentes ativos na dissecação do relevo, os rios também estão condicionados às características das estruturas que compõem a paisagem.

A alteração dos níveis de base está ligada a diferentes fatores (naturais e antrópicos) e ocasiona ajustes em perfis longitudinais, identificados por meio de knickpoints ao longo dos rios, como demonstraram Howard (1967), Bishop (1995), Zancopé e Perez Filho (2009) e Ambili e Narayana (2014). Do mesmo modo, essas anomalias no perfil são condicionadas por mudanças nos fluxos hidrológicos e processos de sedimentação relativos a mudanças e flutuações climáticas, sendo, portanto, o perfil longitudinal um resultado da interação entre aspectos litológicos, tectônicos e climáticos (Stock; Montgomery, 1999; Larue, 2008; Ambili; Narayana, 2014).

Ambili e Narayana (2014) afirmam que o perfil longitudinal dos rios pode apresentar deformações na morfologia geral decorrentes de atividades tectônicas e, portanto, os knickpoints estão associados aos lugares onde a mudança no gradiente do rio é rápida. Para Bishop e outros (2005), as rupturas no perfil longitudinal podem ser causadas por litotipos mais resistentes e erosão diferencial, um aumento na tensão de cisalhamento e por soerguimentos, marcando o limite entre o steady state e o desajustamento da paisagem.

Desse modo, as anomalias em perfis podem indicar um fluxo em desequilibrio onde o recuo da montante indica mudanças no nível de base, no vale ou, em alguns casos, um equilibrio dinâmico entre processos fluviais e movimentos tectônicos (Bishop et al., 2005). No entanto, verifica-se que, em ambientes tropicais úmidos com predominância de rocha sedimentares e situados em pontos intraplaca, é difícil identificar (re)organizações recentes da rede de drenagem, o que demanda formas indiretas de investigação como as morfometrias e técnicas de datação absoluta.

A bacia do ribeirão Araquá, na região centro-oriental do estado de São Paulo, apresenta formas e feições vinculadas a uma possível reorganização da rede drenagem como consequência de mudanças na dinâmica fluvial, indicando ajustes no nível de base regional e local durante o Quaternário. $\mathrm{Na}$ área em questão, encontram-se anomalias de drenagem, formas de relevo retilíneas e níveis de altos terraços apresentando linhas de cascalhos soterrados, as quais podem ter sido originadas a partir de ajustes da drenagem em concomitância com o abatimento de blocos (Facincani, 2000). Embora eventos neotectônicos sejam reconhecidos regionalmente e na área estudada (Penteado, 1968; Etchebehere, 2000; Etchebehere et al. 2004; Sousa, 2002; Pinheiro, 2014), as formas resultantes e a possível idade desses ajustes são ainda pouco esclarecidos. Assim, aventa-se a hipótese de que eventos neotectônicos e climáticos ocorridos no Quaternário tenham influído na reorganização da rede de drenagem e na elaboração dos altos terraços dessa bacia, sobretudo em conformidade com 
as linhas de cascalhos inhumados. Nesse contexto, o principal objetivo deste trabalho é investigar a relação entre a neotectônica, regime tectônico vigente desde o Neógeno (Hasui, 1990; Saadi, 1993), e os eventos climáticos com as mudanças na dinâmica fluvial da bacia do ribeirão Araquá.

\section{Área de estudo}

A área de estudos fica na região centro-oriental do estado de São Paulo, abrange a província tectônica Paraná (Almeida et al., 1981) e ocupa, geomorfologicamente, parte da Depressão Periférica Paulista e das escarpas de cuestas (Ab’Sáber, 2010a, 2010b; Almeida, 1949, 1964), as quais se constituem como limite de um planalto homoclinal localizado a oeste do estado de São Paulo. É importante mencionar que a gênese desses relevos está ligada aos processos de circundesnudação ocorridos a partir do Eoceno (Ab’Sáber, 2010a, 2010b; Pinheiro; Queiroz Neto, 2014) (Figura 1).

Figura 1 - Localização da bacia no estado de São Paulo e litologias presen-

\section{tes na área}

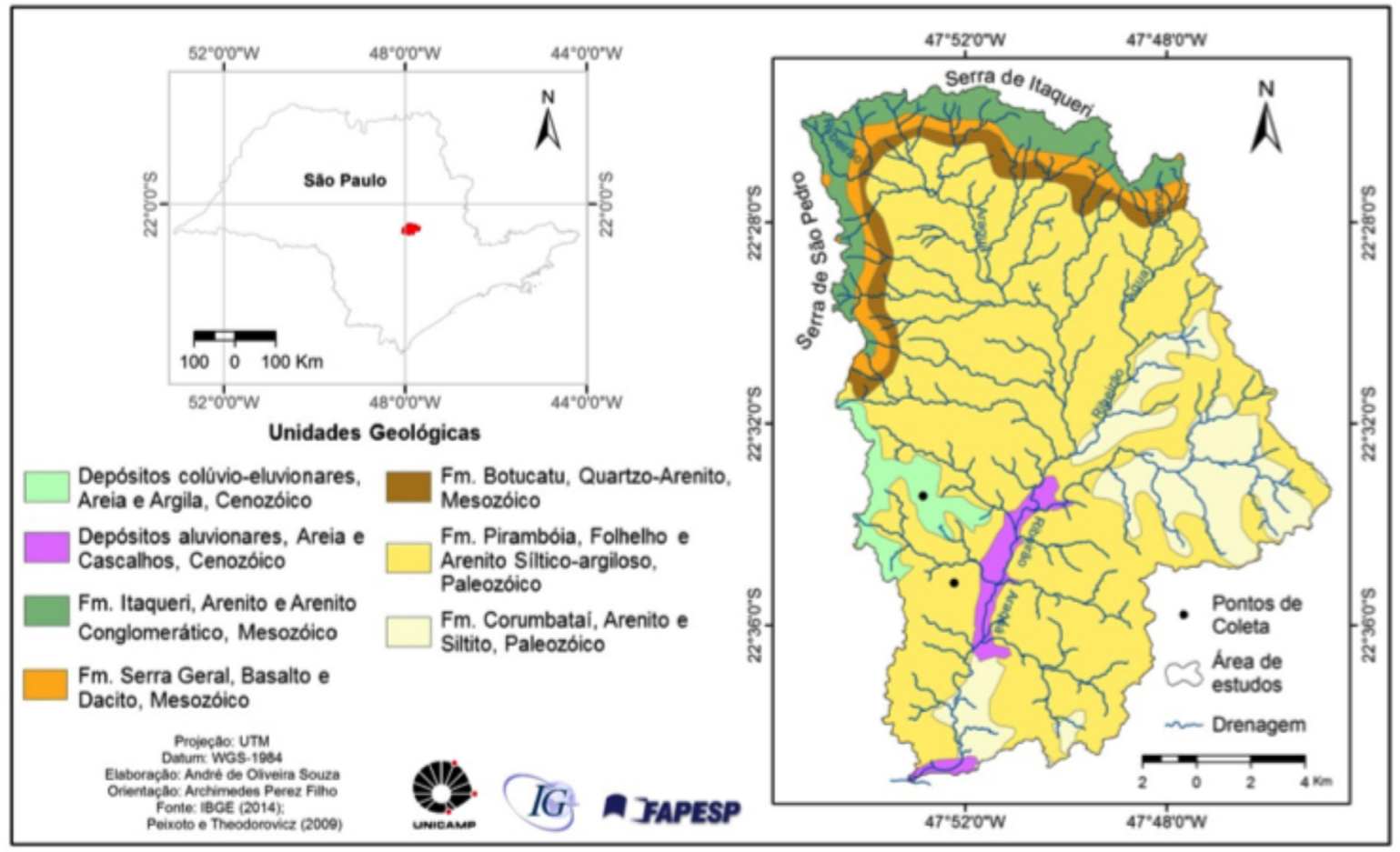

Nesse sentido, o ribeirão Araquá, afluente do rio Piracicaba, insere-se na Zona do Médio Tietê, delimitação realizada por Almeida (1964) para a Depressão Periférica Paulista e que, segundo Penteado (1976), apresenta relevo diversificado, sendo a percée do Tietê, o ponto em que este rio rompe a Serra Geral, o trecho mais marcante. Importante mencionar que a bacia apresenta padrão de drenagem subdendrítico e drena uma área aproximada de 279,20 km², abrangendo parte dos municípios de São Pedro e Charqueada-SP.

As altitudes mais elevadas da bacia estão na Serra de São Pedro e Serra de Itaqueri (> 800 m) (Figura 2). De acordo com Penteado (1976), a primeira está em desnível topográfico com a Serra de Itaqueri, situação que seria relativa a controles tectônicos. Segundo Melo (1995), identificam-se na bacia e adjacências cinco níveis topográficos: Nível Planáltico I (720 a 800 m de altitude), Nivel Planáltico B (610 a 750 m), Nível Planáltico Bd (550 a 680 m) e Nível Planáltico R (590 m). 
No que tange às litologias ígneas, identificam-se na área basaltos e dacitos (Peixoto; Theodorovicz, 2009), responsáveis pela sustentação do relevo de cuestas e que, segundo Almeida e Carneiro (2004), vinculam-se ao magmatismo alcalino e localmente efusivo ocorrido em diversas regiões entre o Triássico e o Eocretáceo.

Sobrepostas aos basaltos da Fm. Serra Geral e, localmente, sobre os arenitos eólicos da Fm. Botucatu, encontram-se litotipos correlacionados à Fm. Itaqueri. Segundo Etchebehere e outros (2004), esse grupo litológico compõe as coberturas sedimentares pós-basaltos, que também abrangem a ampla sedimentação cretácea e a mais restrita sedimentação cenozoica que é constituída por alternâncias de fácies arenosas, conglomeráticas e argilosas; o que sugere que houve variações nos níveis de energia dos agentes de transporte. Apesar de estudos discutirem a gênese dessa unidade geológica, ainda não há consenso quanto à idade de sua formação (Riccomini, 1997; Santos; Ladeira, 2006); de modo que ora é considerada do Cenozoico, ora do Mesozoico. Neste trabalho, segue-se a proposta de Peixoto e Theodorovicz (2009), que situa as litologias dessa formação no Mesozoico (Cretáceo Superior).

As formações mais recentes espacializadas pela bacia do ribeirão Araquá têm várias conceituações (Björnberg, 1965; Björnberg; Landim, 1966, Penteado, 1976; Massoli, 1980), que, no contexto mais amplo, compreendem material muito similar. Sendo assim, Massoli (1980) aponta a presença da Formação Santa Rita do Passa-Quatro de idade quaternária, constituída preferencialmente de arenitos mal consolidados. Segundo o autor, os sedimentos dessa formação constituem-se de depósitos arenosos com no máximo $10 \mathrm{~m}$ de espessura, capeando antiga superfície de erosão. Na base, apresentam linhas de seixos ou cascalheiras, representadas por seixos de quartzo e fragmentos de limonita.

\section{Figura 2 - Mapa hipsométrico da bacia do ribeirão Araquá}

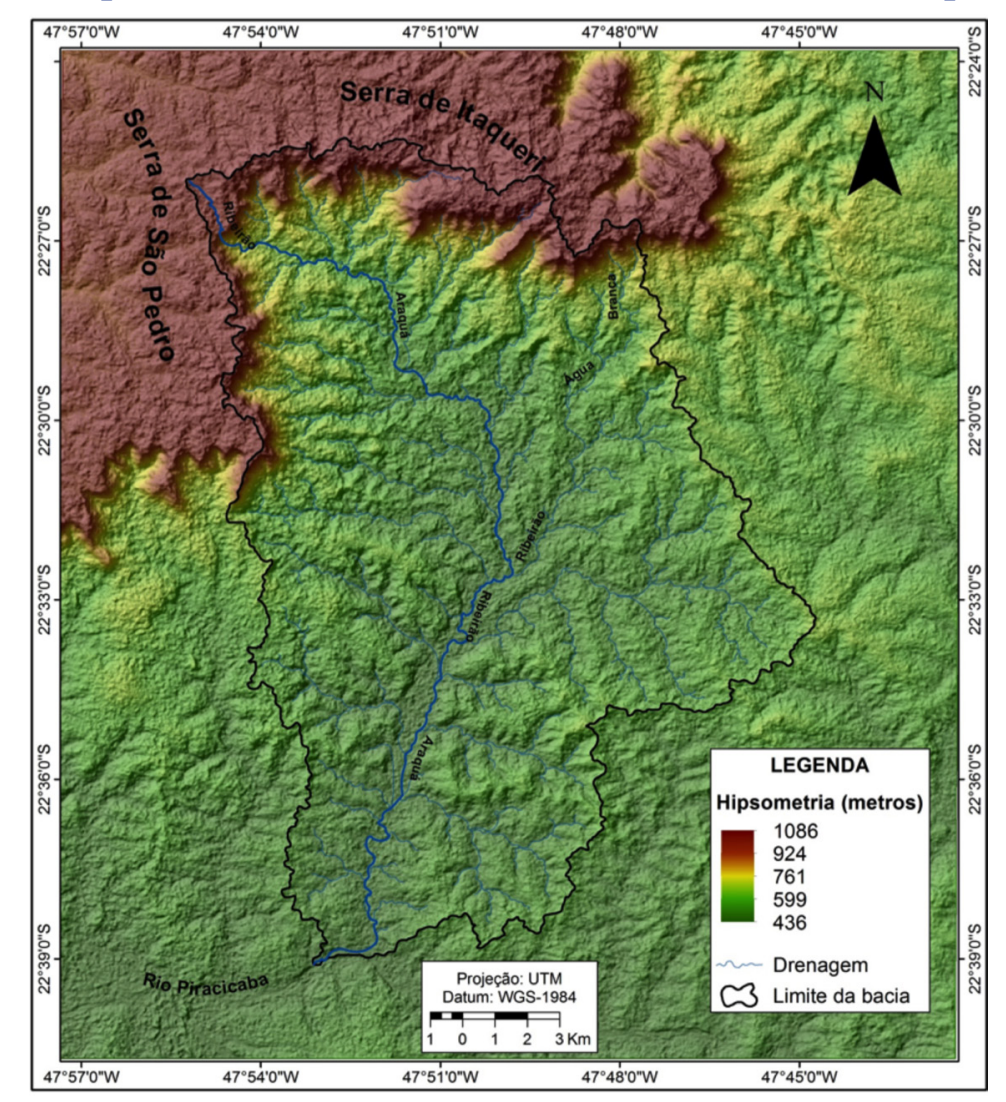

fonte: Aster Gdem (2014). 
Segundo Melo (1995), na área de estudos predominam depósitos areno-argilosos relativamente extensos e delgados sem estruturas sedimentares. De acordo com o autor, esses depósitos estão em diferentes cotas altimétricas, ligadas a diferentes níveis planálticos (I, B, Bd).

No âmbito estrutural, Riccomini (1997) destaca movimentos transcorrentes relativos a estruturas que controlam importantes sistemas fluviais regionais como o rio Tietê (NW) e o rio Mogi Guaçu (NNW) e ao alinhamento São Carlos-Leme (WNW). Sousa (2002) também identificou lineamentos de orientações E-W e N-S na bacia do rio Corumbataí, adjacente à área de estudos. Penteado (1968, 1976), Björnberg (1965) e Björnberg e Landim (1966) também apontaram a existência de importantes formas e feições alinhadas regionalmente nas orientações ENE-WSW, NNE-SSW, NW-SE e falhamentos secundários de orientações SW-NE e NNW-SSE, que inclusive foram responsáveis pela sedimentação dos materiais que recobrem alguns interflúvios na bacia do rio Corumbataí.

Santos e Ladeira (2006) encontraram evidências de ajustes tectônicos cenozoicos em perfis lateríticos na Serra de Itaqueri que, de acordo com os autores, estão relacionadas a faIhas de diferentes orientações: NE-SW, NW-SE, E-W e N-S. Nesse sentido, Pinheiro (2014) aponta a importância dos lineamentos no condicionamento dos canais de primeira e segunda ordem. Para o autor, são predominantes lineamentos NW-SE, N-S e WNW-ESE que provavelmente estão vinculados a regimes de tensões sub-horizontais orientados para NW-SE $(\sigma \mathrm{l})$ e NE-SW ( $\sigma 3)$.

Sendo assim, a bibliografia aponta a importância das falhas na dinâmica do relevo da região, sobretudo naquelas próximas à Estrutura de Pitanga (Sousa, 2002; Etchebehere; Casado; Morales, 2011) e, mesmo que os rejeitos não sejam expressivos, o indicativo de deformações neotectônicas possivelmente associa-se a movimentações contínuas, como infere Pinheiro (2014).

Na década de 1930, Oppenheim e Malamphy (1936) identificaram um setor rebaixado na área abrangida pela bacia do ribeirão Araquá, o qual denominaram Depressão de São Pedro. Segundo os autores, o graben de São Pedro, em conjunto com a elevação do horst de Pitanga, indica um sistema de falhas regionais com reduzida projeção vertical dispostas en echelon de leste para oeste, compondo um conjunto de depressões na Depressão Periférica Paulista. De acordo com Pinheiro (2014), a hipótese da existência de uma depressão é reforçada pelas cotas do topo da Formação Irati, determinadas a partir dos dados de sondagens realizadas na região e que apontam movimentos lentos porém constantes de processos de epirogênese positiva e negativa que influenciam a dissecação de setores dos pedimentos/glacis presentes no ribeirão Araquá.

Por fim, quanto a solos, coexistem na área ampla variedade de classes, com destaque aos latossolos vermelho-amarelo (Carpi Junior, 1996), argissolos na Depressão Periférica e neossolos quartazarênicos (Oliveira, D., 1992) recobrindo parte dos pedimentos identificados na área, além de neossolos litólicos e cambissolos nas escarpas das serras de Itaqueri e São Pedro (Oliveira, J.; Jacomine, Camargo, 1992).

\section{Material e métodos}

A análise das mudanças na dinâmica fluvial da bacia do ribeirão Araquá baseou-se na correlação entre os seguintes índices morfométricos: (1) relação declividade-extensão (RDE), (2) fator de simetria topográfica transversal, (3) fator de assimetria de bacias de drenagem 
(FABD) com os (4) knickpoints identificados nos perfis longitudinais. Também se fizeram (5) análises dos lineamentos pelo sombreamento do DEM (hillshade) e (6) datação por luminescência opticamente estimulada (LOE) dos sedimentos localizados acima e abaixo da linha de cascalhos (Quadro 1).

\section{Quadro 1 - Síntese das técnicas utilizadas}

\begin{tabular}{|c|c|c|}
\hline metodologia & objetivo & chaves de interpretação \\
\hline $\operatorname{RDE}^{(1)}$ & $\begin{array}{l}\text { Identificar anomalias no perfil longitudinal que } \\
\text { podem estar associados a falhamentos ou } \\
\text { controles litológicos }\end{array}$ & $\begin{array}{l}<2: \text { sem anomalia } \\
\geq 2 \text { e }<10: \text { anomalias de segunda ordem } \\
\geq 10 \text { anomalias de primeira ordem }\end{array}$ \\
\hline FATT $^{(2)}$ & $\begin{array}{l}\text { Avaliar trechos assimétricos do rio e possíveis } \\
\text { migrações lateral dos cursos }\end{array}$ & $\begin{array}{l}\text { Quanto mais próximo de 1, maior a será a } \\
\text { assimetria }\end{array}$ \\
\hline $\mathrm{FABD}^{(3)}$ & $\begin{array}{l}\text { Avaliar o grau de deslocamento do canal } \\
\text { principal em relação ao centro geométrico da } \\
\text { bacia. } \bigcirc \text { afastamento pode estar associado a } \\
\text { eventuais basculamentos de blocos }\end{array}$ & $\begin{array}{l}\text { próximo ou igual a 50: sem basculamento } \\
>50 \text { : basculamento da margem direita } \\
<50 \text { : basculamento da margem esquerda }\end{array}$ \\
\hline perfil longitudinal ${ }^{(4)}$ & $\begin{array}{l}\text { Avaliar as eventuais anomalias do perfil } \\
\text { longitudinal }\end{array}$ & $\begin{array}{l}\text { Quanto à linha de tendência } \\
\text { acima: anomalias posivitas } \\
\text { abaixo: anomalias negativas }\end{array}$ \\
\hline $\begin{array}{l}\text { análise de lineamen- } \\
\text { tos }^{(5)}\end{array}$ & $\begin{array}{l}\text { Identificar lineamentos e avaliar sua influência } \\
\text { na rede de drenagem e controles na dinâmica } \\
\text { erosiva da área }\end{array}$ & $\begin{array}{l}\text { Diferentes orientações conforme as } \\
\text { zonas de cisalhamentos regionais }\end{array}$ \\
\hline datação por $\operatorname{LOE}^{(6)}$ & $\begin{array}{l}\text { Identificar diferentes eventos } \\
\text { deposicionais }\end{array}$ & Idades até $1 \mathrm{Ma}$ antes do presente \\
\hline
\end{tabular}

Referenciais teóricos: Hack (1973), (4) Etchebehere (2000), Etchebehere et al. (2004) e Seeber e Gornitz (1983). Cox (1994) ${ }^{(2)}$ e Ibanez e Riccomini (2011). Hare e Gardner (1984), (3) Salamuni, Ebert e Hasui (2004), Bishop (1985) e Guedes e outros (2006). Riccomini e Crósta (1988), ${ }^{(5)}$ D. B. Oliveira e outros (2009) e Corrêa e Fonsêca (2010). Sallun e outros (2007). ${ }^{(6)}$

Os aspectos geomorfológicos relativos às deformações neotectônicas foram analisados a partir de cartas topográficas dos municípios de São Pedro e Itirapina na escala 1:50.000, ambas produzidas pelo Instituto Brasileiro de Geografia e Estatística (IBGE) nas décadas de 197080, e trabalhos de campo. Além disso, foram utilizados recortes de imagens Aster Gdem da área e das adjacências, bem como o software ArcGis 10.3, para o mapeamento dos lineamentos e obtenção das variáveis utilizadas na morfometria.

\section{Relação declividade-extensão (RDE)}

Foi realizada a partir das propostas de Hack (1973) e amplamente divulgada no Brasil por Etchebehere (2000). Segundo esses autores, o índice permite identificar anomalias no perfil longitudinal de um rio e pode ser determinado a partir da seguinte equação:

$$
\mathrm{RDE}=\Delta \mathrm{h} / \Delta \mathrm{l} \mathrm{XL} \div \Delta \mathrm{h}^{*} / \log \mathrm{L}^{*}
$$


Onde:

$\Delta \mathrm{h}^{*}=$ amplitude altimétrica

$\Delta h=$ equidistância entre as curvas de nível

$\Delta \mathrm{l}=$ medida do curso em linha reta

$\mathrm{L}=$ comprimento efetivo da drenagem no intervalo da curva de nível analisada até a cabeceira da drenagem

$L^{*}=$ comprimento total do rio analisado

\section{Fator de assimetria topográfica transversal (FSTT)}

O fator de assimetria topográfica transversa (FSTT) foi analisado a partir das propostas de Cox (1994) e lbanez e Riccomini (2011), a que se aplica a seguinte equação.

$$
\mathrm{T}=\mathrm{Da}-\mathrm{Dd}
$$

Onde:

$\mathrm{Da}=$ distância entre a linha média da bacia (basin midline) e o divisor topográfico da margem direita do rio

$\mathrm{Dd}$ = distância entre a linha média do rio analisado (meanderbelt midline) e a linha média da bacia

Para adotar esse método, optou-se por calcular os valores a partir de seções transversais, separadas por uma distância de 1.000 m; salienta-se que o índice foi aplicado ao rio principal da bacia.

\section{Fator de assimetria de bacia de drenagem (FABD)}

$O$ fator de assimetria de bacia de drenagem é um índice que avalia o grau de deslocamento do canal principal da bacia e, desse modo, é possível inferir basculamentos de blocos, bem como a margem onde predomina a migração lateral (Hare; Gardner, 1984), sendo determinado a partir da equação abaixo.

$$
\mathrm{FA}=100(\mathrm{Ar}-\mathrm{At})
$$

\section{Onde:}

$\mathrm{Ar}=$ área correspondente à margem direita da bacia

At $=$ área total da bacia

De acordo com Salamuni, Ebert e Hasui (2004), os valores de FABD iguais ou próximos a 50 sugerem pouca ou nenhuma atividade tectônica, enquanto os acima de 50 indicam um provável basculamento da margem direita do rio e os inferiores sugerem um provável basculamento da margem esquerda. 


\section{Perfil longitudinal}

$\bigcirc$ perfil longitudinal consiste em um gráfico em cujo eixo das abcissas são expressos os valores correspondentes ao comprimento do rio e, no das ordenadas, os valores relativos à altimetria. Para avaliar possíveis anomalias, traça-se uma linha de tendência (curva teórica de equilibrio) logarítmica, que permite comparar as variações do perfil real do rio com a curva teórica de equilibrio fluvial, como propõem Hack (1973), Bishop (1985), Bishop e outros (2005) e Guedes e outros (2006). Nesse modelo, são considerados anômalos os trechos do rio acima da linha de tendência (anomalia positiva) e abaixo (anomalias negativas) dela. Em ambos os casos, esses knickpoints correspondem a setores em desequilibrio e que podem corresponder tanto a controles estruturais, diferenças na erodibilidade dos litotipos, mudanças climáticas e sedimentação acelerada.

Na área de estudos, aplicou-se o RDE e se fez o perfil longitudinal dos dois cursos mais importantes - o ribeirão Araquá, rio principal, e o ribeirão Água Branca, afluente da margem esquerda -, usando curvas de nível com equidistância de $20 \mathrm{~m}$, as quais foram elaboradas a partir do DEM.

\section{Análise de lineamentos}

Os lineamentos correspondentes a trechos de rios retilíneos, interflúvios e escarpas alinhadas foram extraídos manualmente por meio da análise DEM, sombreados (hillshade) em 4 azimutes: $180^{\circ}, 360^{\circ}, 315^{\circ}$ e $45^{\circ}$ no software ArcGis 10.3 que, posteriormente subsidiaram a elaboração do mapa de lineamentos. Menciona-se que essa metodologia procurou seguir as propostas de Riccomini e Crósta (1988), D. B. Oliveira e outros (2009), Corrêa e Fonsêca (2010). Os dados obtidos permitiram a elaboração do gráfico de rosetas no software StereoNet, bem como a obtenção da densidade de lineamentos em $\mathrm{km} / \mathrm{km}^{2}$, obtida a partir de um raio de $700 \mathrm{~km}^{2}$.

\section{Luminescência opticamente estimulada (LOE)}

No presente estudo, as datações foram realizadas pela técnica do LOE em 4 amostras coletadas em dois níveis de altos terraços fluviais e em profundidades diferentes (abaixo e acima de cada linha de cascalho). Posteriormente, as idades foram obtidas a partir da aplicação do método SAR (Single-Aliquot Regenerative-Dose), como proposto por Murray e Wintle (2000). O referido método tem sido utilizado em ampla bibliografia nacional e internacional, justificando, assim o seu uso nessa pesquisa. Os procedimentos técnicos foram realizados no Laboratório de Datação, pelo Dr. Silvio Luiz Miranda Brito.

\section{Resultados e discussão Índices morfométricos}

RDE do ribeirão Araquá (Figura 3) apontou valores que são considerados anomalias de primeira e segunda ordem. Na cota de 900 m de altitude, destaca-se o valor de 4,68, relativo ao contato erosivo entre os dois compartimentos geomorfológicos, evidenciados sobretudo pela ruptura topográfica relativa à serra de São Pedro e Itaqueri. 
Figura 3 - Perfil longitudinal do ribeirão Araquá

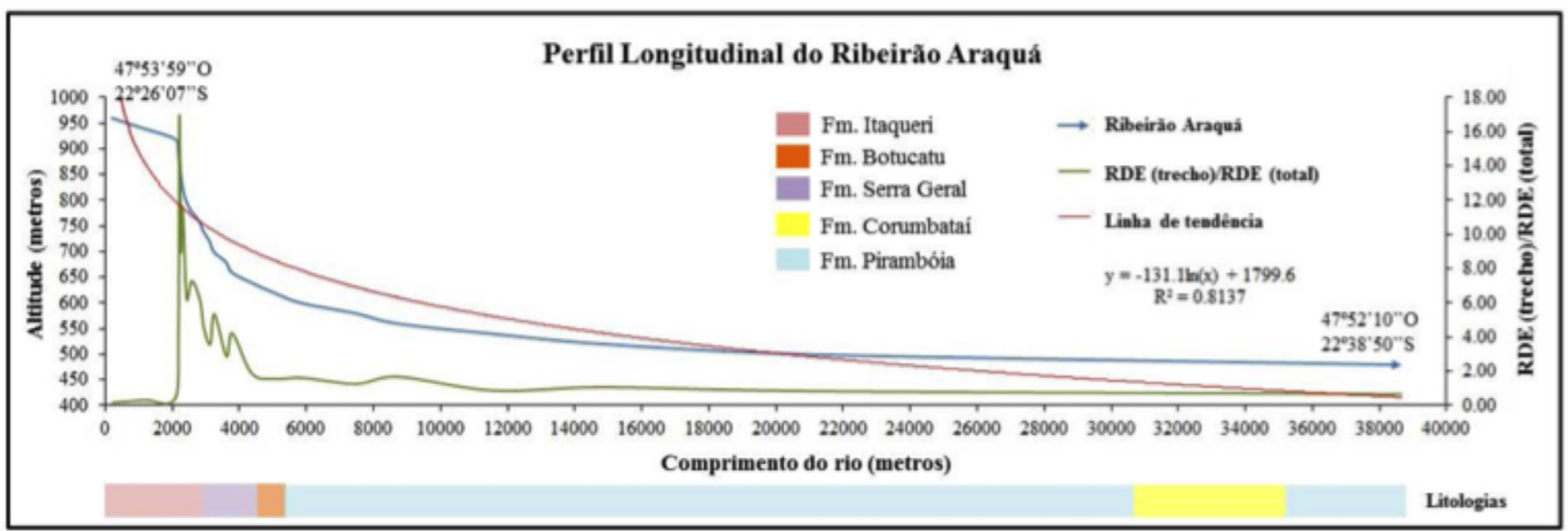

legenda: linha verde: valores de RDE - linha vermelha: linha de tendência - linha azul: perfil do rio

Nas cotas altimétricas acima de 880 m, são identificados os maiores valores do índice RDE do ribeirão Araquá, e, apesar do aspecto topográfico mencionado acima, é importante salientar que nesse setor também se identificaram lineamentos com orientações E-W, que podem estar vinculados à presença de falhas transcorrentes, tendo em vista a espacialização anômala da drenagem representada por curvas abruptas e possíveis shutter ridges (Figura 4). Nesse setor, o ribeirão Araquá desvia seu curso para leste e em seguida retoma seu traçado para sul, caracterizando um aspecto em S da drenagem. Entretanto, é importante mencionar que também se verifica importantes variações litológicas que, em conjunto com os aspectos estruturais, pode ser responsável pelos valores apontados. Anomalias nos valores de primeira e segunda ordem também foram identificadas nas cotas de 800 a 660 m e provavelmente estão relacionadas a aspectos litológicos correspondentes às variações de arenitos Botucatu e basaltos.

Figura 4 - Localização de curvas abruptas no alto curso

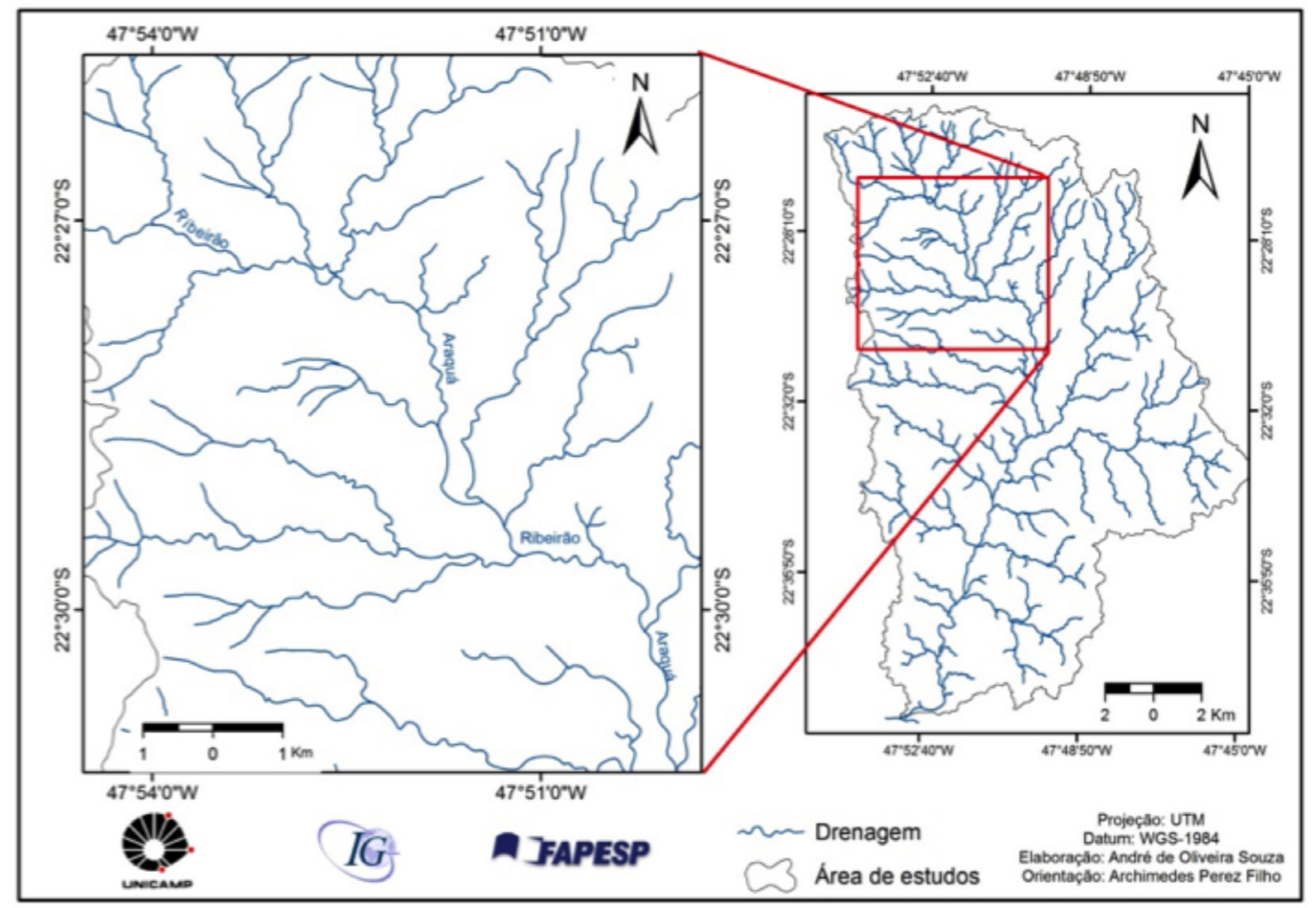


O FATT (Figura 5) apontou trechos do ribeirão Araquá de significativa assimetria, sobretudo no alto curso, onde os valores de $T$ se aproximam de 1 . Os valores obtidos sugerem controles litoestruturais, pois alinhados à disposição da rede de drenagem, também são verificados valores expressivos do índice RDE, significativas rupturas no perfil longitudinal nesse trecho do rio, variações litológicas e presença de lineamentos. Destaca-se que, na Serra de São Pedro, Pinheiro (2014) também acusou a presença de facetas triangulares, indicando a possibilidade de que elas estejam relacionadas a eventos neotectônicos.

\section{Figura 5 - Valores do fator de simetria topográfica transversal}

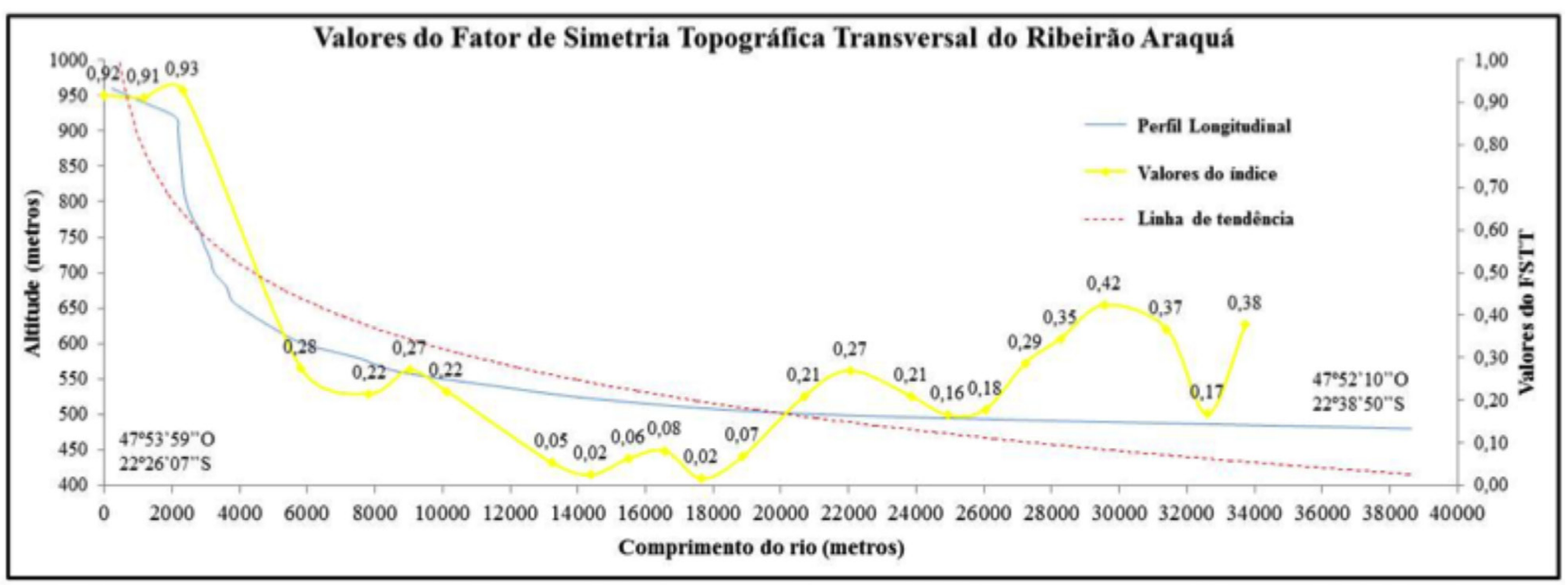

legenda: linha azul: ribeirão Araquá - linha amarela: índice FSTT - linha laranja: linha de tendência logarítmica do ribeirão Araquá

No baixo e médio curso, os valores indicaram pouca assimetria do rio, que inclusive em alguns trechos apresenta significativa simetria das margens ( $T$ próximo de 0 ), como se observa na sobreposição do perfil longitudinal com os valores obtidos.

No baixo curso, como mencionado, esses aspectos geomorfológicos possivelmente estão relacionados a controles por falhas de orientação N-S, identificadas no relevo pela retilinearidade de trechos do Araquá. Além disso, a maior dissecação dos pedimentos situados na margem direita desse rio parece estar associada ao sutil basculamento da margem esquerda e a contínua subsidência da Depressão de São Pedro, concordando em parte com as proposições de Pinheiro (2014). Segundo o autor, o soerguimento de setores correspondentes ao baixo curso tem proporcionado a intensificação dos processos erosivos e, consequentemente, a dissecação dos pedimentos; do mesmo modo, a subsidência do médio e alto curso do Araquá tem conduzido a preservação dos pedimentos desse trecho. Entretanto, verifica-se que os glacis presentes na margem direita estão significativamente degradados pela drenagem atual, situação que pode estar relacionada ao basculamento e à consequente migração do ribeirão Araquá.

Além disso, verificou-se em campo que os altos terraços da margem esquerda, a $594 \mathrm{~m}$ de altitude, estão em posição topográfica superior aos da margem direita (570 m de altitude) que, em conjunto com a presença de colinas residuais (651-700 $\mathrm{m}$ de altitude) na margem esquerda, corrobora a hipótese aventada (Figura 6).

No setor correspondente a aproximadamente 20.000 m de comprimento (cota altimétrica de $500 \mathrm{~m}$ ), verificou-se que o ribeirão Araquá apresenta anomalia positiva embora o gradiente de declividade seja menor, sugerindo um sutil soerguimento desse setor e corroborando 
o escalonamento dos níveis de terraços identificados, os quais tiveram os sedimentos datados. Deste modo, é possível inferir que a alteração na dinâmica fluvial poderia ser responsável pela gênese dos terraços como consequência de ajustes no nível de base em decorrência de deformações neotectônicas, tendo em vista que aspectos similares são encontrados no ribeirão Água Branca, afluente da margem esquerda da bacia estudada que também apresenta anomalia positiva em seu perfil e altos valores do índice RDE. Destacam-se as considerações de Facincani (2000) e Pinheiro (2014), que identificaram deslocamentos verticais de blocos e soerguimentos na área e adjacências.

Assim, o perfil longitudinal do ribeirão Araquá apresenta alguns knickpoints associados às anomalias positivas e negativas e correspondentes aos valores de outros índices, principalmente do RDE. Verificou-se que, no alto curso, a variação de litotipos, em conjunto com aspectos estruturais (lineamentos e falhas) ou topográficos, é responsável por rupturas no perfil, evidenciando a complexidade de fatores condicionando a espacialização da drenagem.

\section{Figura 6 - Formas e feições geomorfológicas na bacia do ribeirão Araquá}

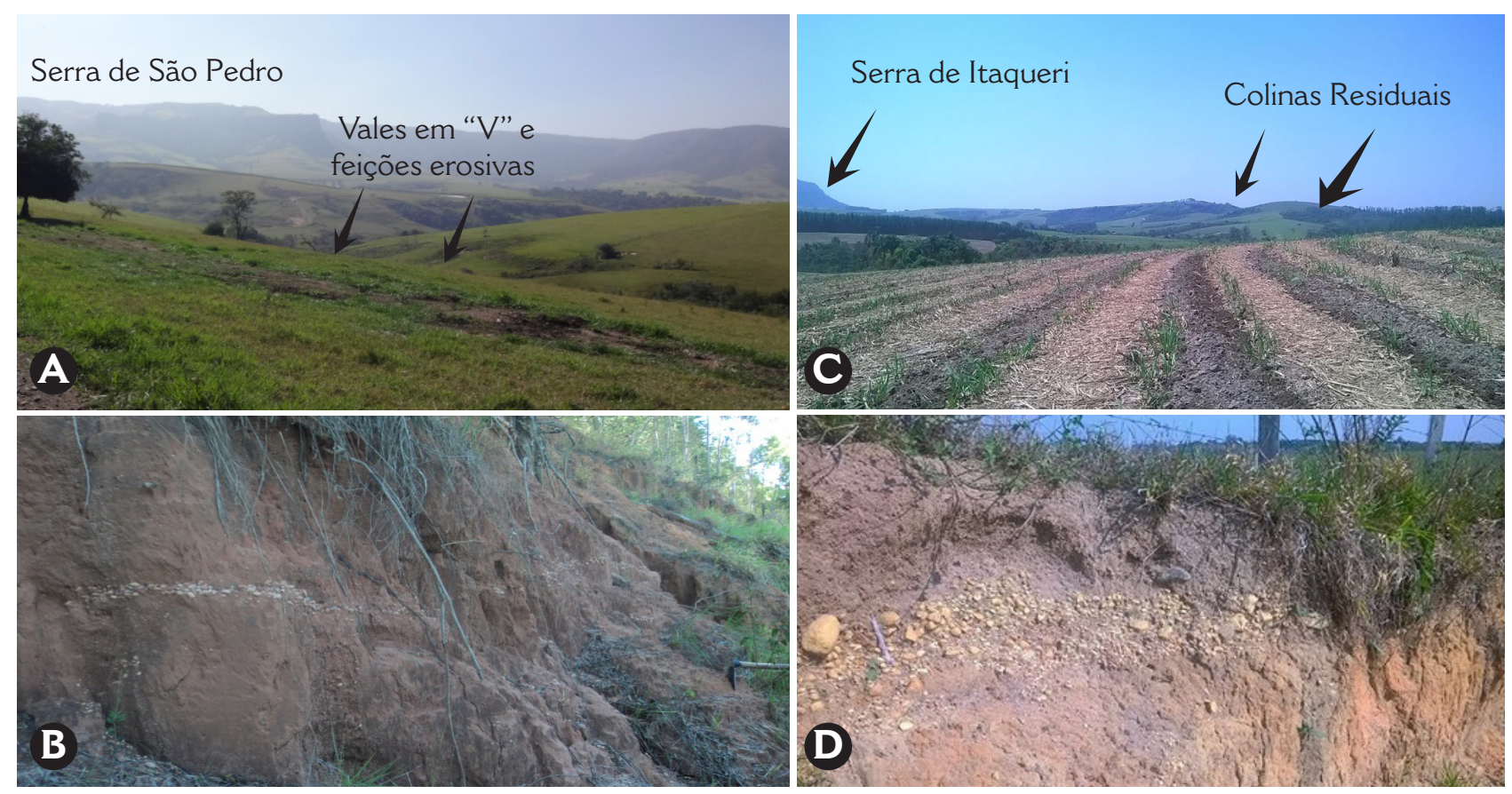

legenda: (A) pedimento dissecado nas proximidades da Serra de São Pedro, (B) relevo acentuado na margem esquerda da bacia, limite entre a bacia do ribeirão Araquá e da bacia do rio Corumbataí, (C) alto terraço da margem direita, (D0) alto terraço da margem esquerda fonte: Fotos de André de Oliveira Souza (2015).

O maior valor anômalo apresentado pelo RDE do ribeirão Água Branca (Figura 7) está na cota altimétrica de $880 \mathrm{~m}$ e corresponde ao setor em que o curso desce a escarpa da Serra de Itaqueri dissecando diferentes litotipos. Neste trecho, foram identificados cursos retilíneos que, possivelmente, correspondem a controles litoestruturais. Essa inferência se deu a partir da sobreposição de lineamentos E-W e N-S na área, que apresenta ainda diferentes litotipos. 


\section{Figura 7 - Perfil longitudinal do ribeirão Água Branca}

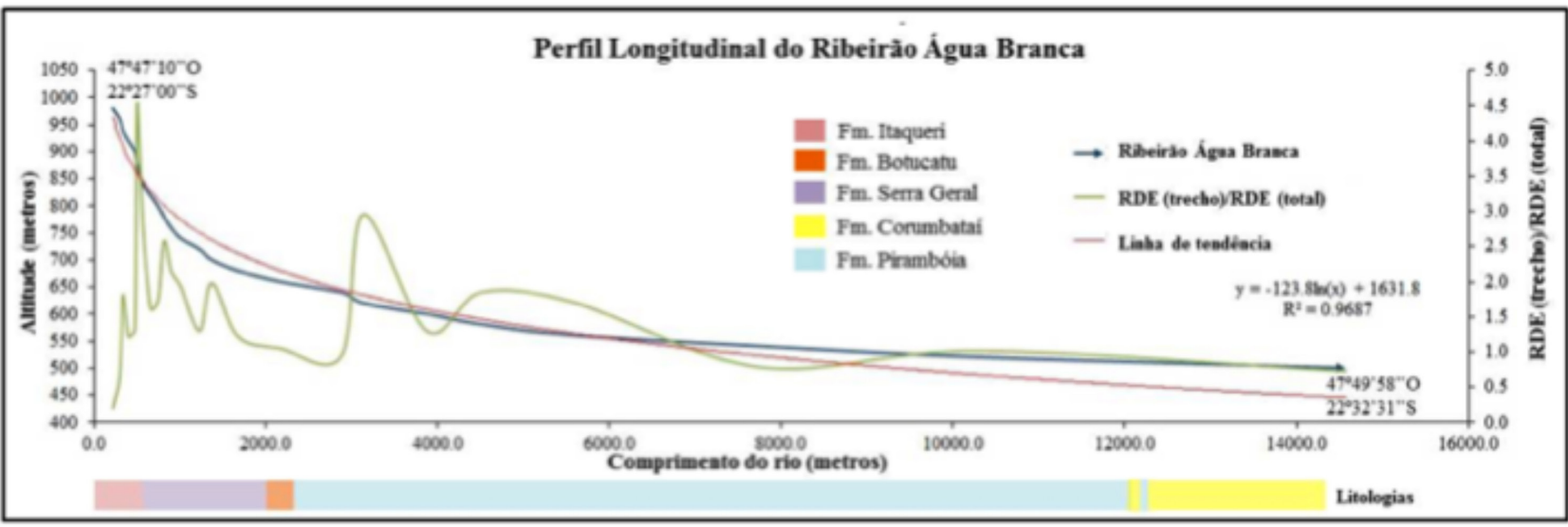

legenda: linha verde: valores do índice RDE - linha vermelha: linha de tendência - linha azul: perfil do rio

Nesse âmbito, os valores do RDE correspondentes às cotas de 860 a $700 \mathrm{~m}$ de altitude, correlacionam-se com as rupturas no perfil longitudinal, indicando que a variabilidade litológica em conjunto com a intersecção de lineamentos de orientação NNW-SSE e E-O também podem ter conduzido a desajustes na dinâmica fluvial e, portanto, os altos valores do índice indicam a sobreposição de controles litoestruturais e possíveis deformações neotectônicas.

As anomalias de primeira ordem identificadas nas cotas de 620 e $580 \mathrm{~m}$ possivelmente estariam relacionadas a falhas de rejeitos verticais, responsáveis pelo controle dos interflúvios que delimitam a parte oeste da bacia hidrográfica estudada, além de ser responsável pelos desvios (elbows) que estão refletidos em knickpoints no perfil longitudinal. Essa hipótese também é aventada no trabalho de Facincani (2000), que reconhece abatimentos de blocos para oeste (margem direita do ribeirão Araquá), reforçando a ideia da existência de uma falha de rejeito vertical orientada aproximadamente para NNW-SSE.

O FABD indicou basculamento para a margem direita (valor de 36,7), o que corresponde às evidências na topografia de uma falha de rejeito vertical relacionada ao interflúvio limite entre a bacia do ribeirão Araquá e o rio Corumbataí, além de anomalias de drenagem e valores significativos dos outros parâmetros flúvio-morfométricos relativos a esse rio. $\bigcirc$ limite entre a as duas bacias hidrográficas é caracterizado por topos de interflúvios alinhados de acordo com a orientação NW-SE e que provavelmente estão relacionadas ao sistema de falha Passa Cinco-Cabeça, considerado por Sousa (2002) o mais importante dentro da Estrutura de Pitanga, onde predominam falhas normais de trend NW-SE.

Os lineamentos cartografados na bacia não têm orientação preferencial (Figura 8), ou seja, existem estruturas com diferentes trends. Sendo assim, é possível afirmar que os alinhamentos e as anomalias de drenagem da bacia hidrográfica do ribeirão Araquá estão ligados a aspectos estruturais locais e regionais e eventos de diferentes idades. Por outro lado, a inexistência de um direcionamento preferencial de alinhamentos na área estudada pode indicar a existência de numerosas falhas e fraturas secundárias locais, estando de acordo com as afirmações de Oppenheim e Malamphy (1936). 


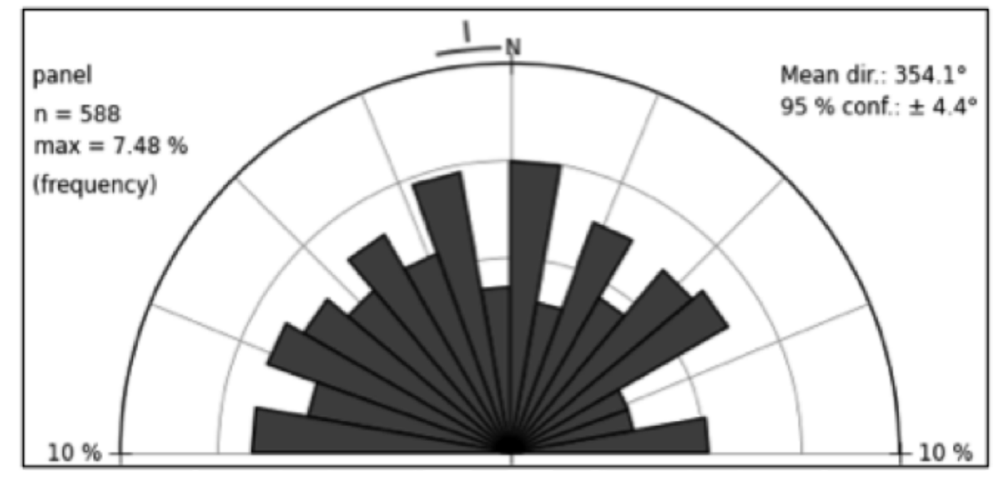

Na Figura 9B, observa-se que, nas áreas correspondentes à anomalia positiva no perfil longitudinal dos dois rios, os lineamentos são mais densos, como em setores a montante. Em conjunto com os outros dados morfométricos, sobretudo do RDE, esse fato corrobora a hipótese de que controles estruturais e aspectos litológicos possam influenciar o desenvolvimento dos perfis longitudinais e, consequentemente, a presença de knickpoints dos rios analisados.

No Córrego da Grama, afluente da margem esquerda do Araquá, são evidentes anomalias de drenagem correspondentes com os principais "feixes" de lineamentos. Em campo, observou-se forte entalhamento dos vales que, do ponto de vista geomorfológico, indica retomada erosiva provavelmente em decorrência do ajuste de níveis de base locais e regionais. Deste modo, os valores expressivos nesse setor, em conjunto com o afloramento da Formação Corumbataí, conduzem à interpretação de que a drenagem é controlada por fatores litoestruturais, assim como é possível que as falhas presentes estejam vinculadas ao soerguimento e basculamento da margem esquerda da bacia do ribeirão Araquá.

\section{Figura 9 - Mapa da análise de lineamentos da bacia do ribeirão Araquá}

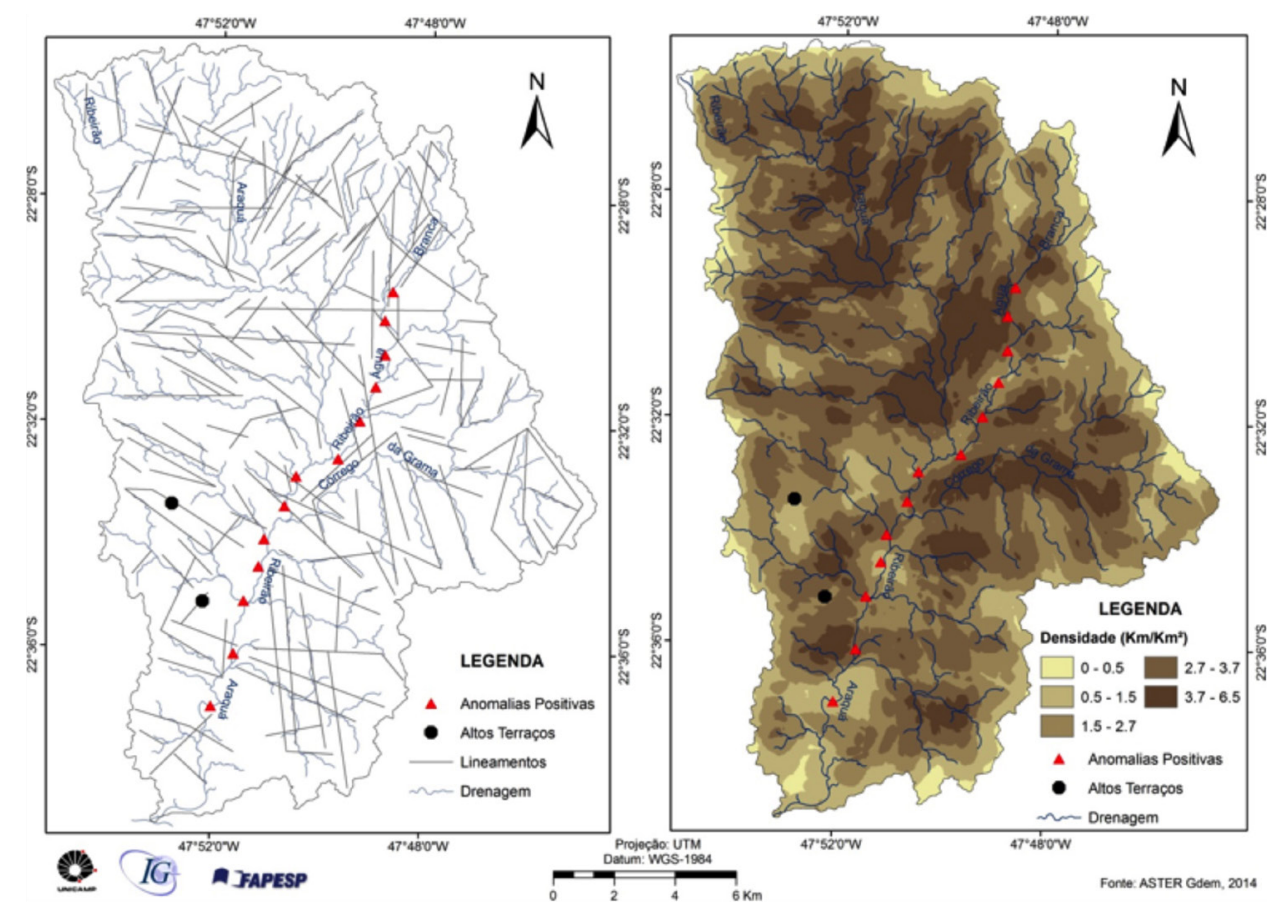

legenda: (A) mapa de lineamentos, (B) mapa da densidade de lineamentos 
No mapa de lineamentos (Figura 9A), é possível observar extensos lineamentos orientados para N-S, E-W e NNW-SSE, sugerindo controle estrutural da rede de drenagem, tal como verificado por Pinheiro (2014) e Pinheiro e Queiroz Neto (2015) em bacias adjacentes à área estudada. Destaca-se ainda a correspondência dos lineamentos cartografados com as anomalias de drenagem, tais como a presença de trechos retilíneos e curvas abruptas.

\section{Geocronologia dos eventos na bacia hidrográfica do ribeirão Araquá}

Como mencionado acima, evidências de eventos neotectônicos na bacia hidrográfica do ribeirão Araquá foram identificadas a partir do uso de índices morfométricos, que apresentaram valores correspondentes entre si e relacionadas a aspectos geomorfológicos, como a presença de facetas triangulares, alinhamentos de interflúvios, anomalias de drenagem e diferentes níveis de altos terraços.

Quanto aos terraços, foram encontrados em dois níveis na margem direita do ribeirão Araquá, mais precisamente nos setores de médio e baixo cursos. Eles estão escalonados provavelmente em decorrência de sucessivas reativações de antigas zonas de cisalhamento que causaram o abatimento dos blocos, formando a Depressão de São Pedro, mencionada no trabalho pioneiro de Oppenheim e Malamphy (1936).

A datação dos sedimentos sobrepostos e sotopostos à linha de cascalheiras do primeiro nível de terraço (60 $\mathrm{m}$ acima do curso principal) (Figura 10) apresentou idades correlacionadas ao Pleistoceno Superior: 59,550 \pm 9,260 A.P para o material acima da cascalheira e 60,000 \pm 7,715 A.P para os sedimentos localizados abaixo da cascalheira. Portanto, é coerente que, no intervalo de tempo entre a deposição dos dois materiais, uma mudança na dinâmica hidrológica induzida provavelmente pela neotectônica tenha sido responsável pelo primeiro registro de reorganização da drenagem da bacia.

\section{Figura 10 - Perfil do primeiro nível de alto terraço - pontos onde foram coletadas as amostras}

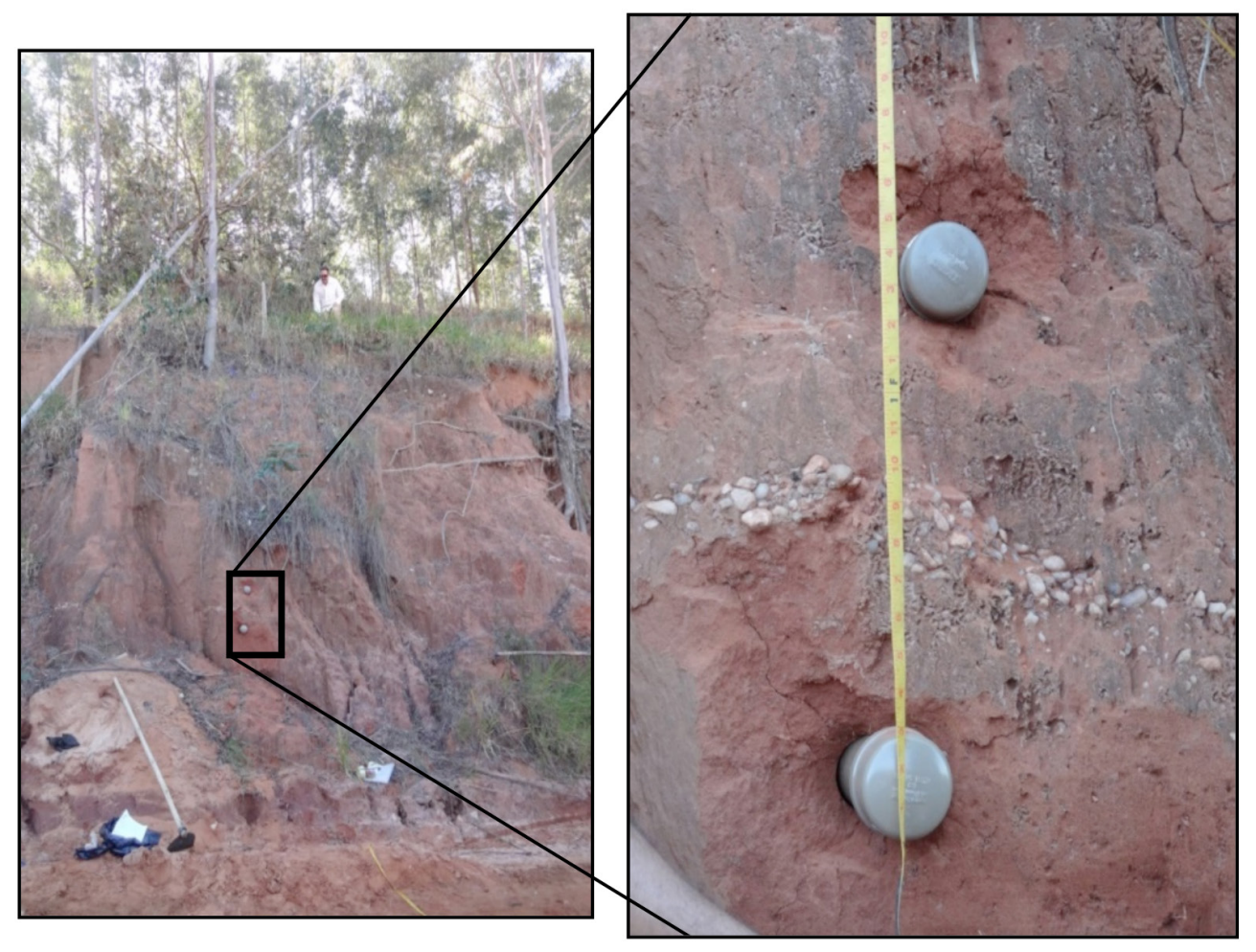

fonte: Fotos de André de Oliveira Souza (17 jun. 2014). 
A hipótese de deformações neotectônicas durante o Pleistoceno Superior é corroborada por levantamentos paleoclimáticos realizados no âmbito do estado de São Paulo e do continente sul-americano (Coltrinari, 1991; Lichte, 1991; Thomas; Thorp, 1995; Scheel-Ybert et al., 2003; Ortiz-Jaureguizar; Cladera, 2006; Thomas, 2008), os quais não observaram oscilações ambientais significativas durante o período em que as idades foram obtidas, afastando a hipótese de que esses terraços estariam relacionados às flutuações do clima pretérito.

Os resultados obtidos a partir das análises morfométricas, somados às observações em campo, bem como as idades obtidas a partir de datação por LOE, permitem inferir dois momentos de desequilibrios fluviais na bacia do ribeirão Araquá durante o Pleistoceno Superior. $\bigcirc$ primeiro teria se iniciado no período em que se formou o nível de terraço mais alto. Um segundo momento de desequilibrio teria ocorrido por volta de $35.000 \pm 2,860$ A.P, quando que se formou o segundo nível de terraço (30 $\mathrm{m}$ acima do rio principal) (Figura 11).

Figura 11 - Perfil do primeiro nível de alto terraço - pontos onde foram coletadas as amostras

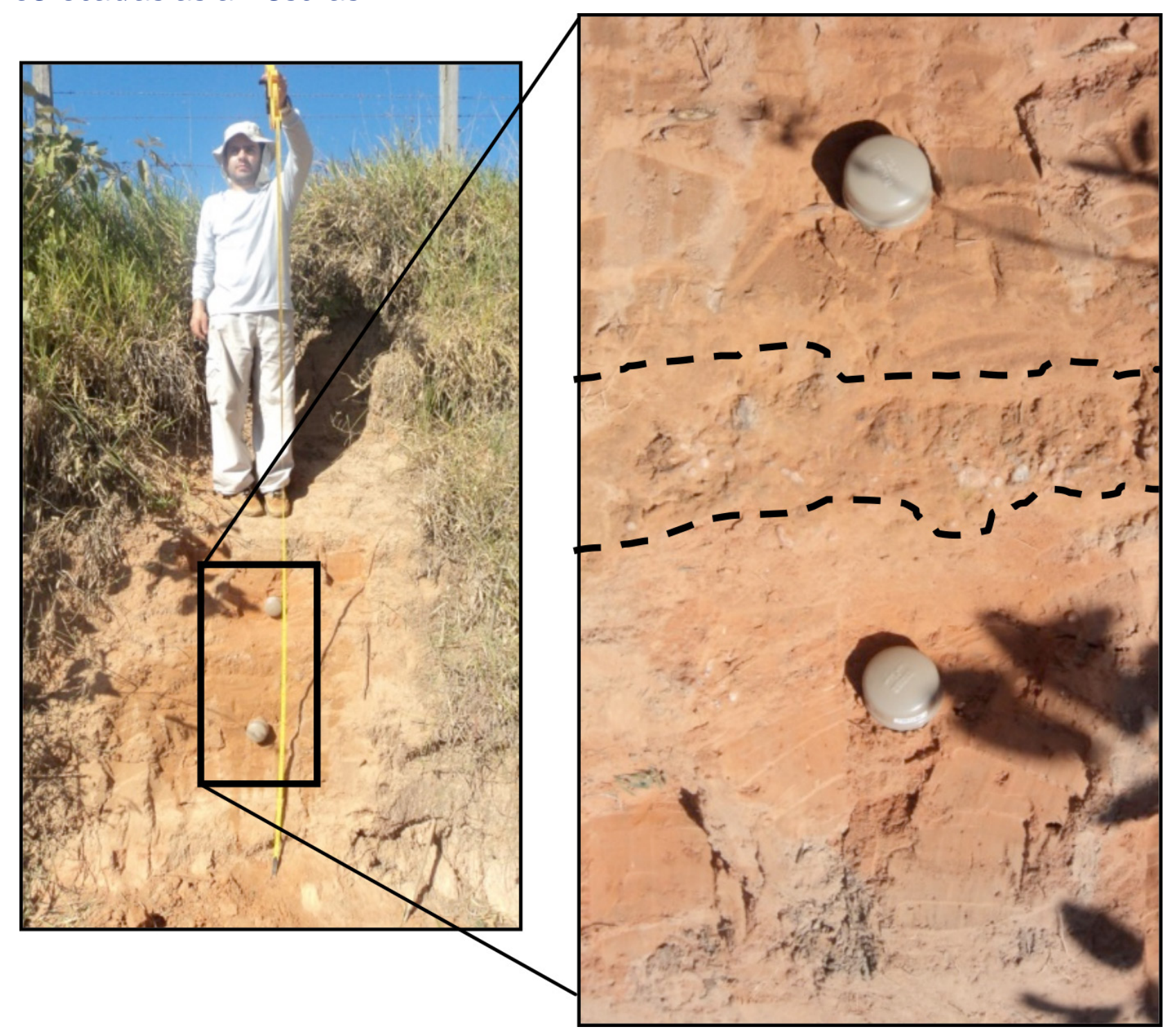

legenda: A linha tracejada delimita a linha de cascalho enterrado. fonte: Trabalho de campo (17 jun. 2014). 
A possibilidade de eventos climáticos terem sido responsáveis pelo ajuste hidrológico da bacia durante a formação do segundo nível de terraço, isto é, entre 35,000 \pm 2,860 A.P (sedimentos subjacentes à linha de cascalho) e 13,900 \pm 940 (para aqueles localizados acima), é reforçada pelos estudos de Rabassa e Clapperton (1990), Coltrinari (1991), Behling (2002) e Rossettie outros (2015), os quais apontam um esfriamento global concomitante à diminuição da umidade e do nível oceânico no Brasil.

\section{Conclusão}

A correspondência entre os valores dos índices morfométricos utilizados na pesquisa aponta a influência de aspectos estruturais e litológicos na espacialização da rede de drenagem, bem como na elaboração das formas de relevo que apresentavam indícios de atividade neotectônica e que influenciaram inclusive a elaboração do nível de terraço mais alto da bacia.

Quanto às idades obtidas em datação por LOE, foi possível identificar dois eventos importantes que modificaram a dinâmica fluvial da bacia. No primeiro, teriam ocorrido reativações neotectônicas que modificaram o nível de base e induziram a formação do nível de terraço mais elevado. No segundo, teriam ocorrido mudanças climáticas que possivelmente influenciaram a formação do nível de terraço mais baixo.

De modo geral, a metodologia aplicada se mostrou eficiente para esclarecer a hipótese levantada neste trabalho e permitiu alcançar os objetivos propostos. No primeiro caso, considera-se que, além de controles litoestruturais, fatores climáticos também condicionaram as mudanças na dinâmica fluvial da bacia do ribeirão Araquá.

\section{Referências}

AB'SÁBER, A. N. Regiões de circundenudação pós-cretáceas no planalto brasileiro. In: MAY C. et al. (Ed.). A obra de Aziz Nacib Ab'Sáber. São Paulo: Beca-Ball, 2010a. p. 40-50.

AB'SÁBER, A. N. A depressão periférica: um setor de áreas de circundenudação pós-cretácica na bacia do Paraná. In: MAY C. et al. (Ed.). A Obra de Aziz Nacib Ab'Sáber. São Paulo: Beca-Ball, 2010b. p. 1390-1395.

ALMEIDA, F. F. M. Fundamentos geológicos do relevo paulista. Geologia do Estado de São Paulo, São Paulo: IGG, n. 41, p. 167-263, 1964.

Relevo de cuesta na bacia sedimentar do rio Paraná. Boletim Paulista de Geografia, São Paulo, n. 3, p. 21-33, 1949.

ALMEIDA, F. F. M.; BARBOSA, O. Geologia das quadrículas de Piracicaba e Rio Claro estado de São Paulo. Boletim da Divisão de Geologia e Mineralogia, Rio de Janeiro, n.143, p.1-96, 1953.

ALMEIDA, F. F. M.; CARNEIRO, C. D. R. Inundações marinhas fanerozoicas no Brasil e recursos minerais associados. In: MANTESSO NETO, V. et al. (Org.). Geologia do continente sul-americano: evolução da obra de Fernando Flávio Marques de Almeida. São Paulo: Beca, 2004. v. 1. p. 43-58. 
ALMEIDA, F. F. M. et al. Brazilian structural provinces: an introduction. Earth Science Review, Amsterdã, v. 17, n. 1/2), p. 1-29, 1981.

AMBILI, V.; NARAYANA, A. C. Tectonic effects on the longitudinal profiles of the Chaliyar River and its tributaries, southwest India. Geomorphology, v. 217, p. 37-47, 2014.

BARRETO, M. M. R. Geomorfologia da área de São Pedro (SP). Notícia Geomorfológica, Campinas-SP, v. 10, n. 19, p. 47-61, jun. 1970.

BEHLING, H. South and Southeast Brazilian grassland during Late Quaternary times: a synthesis. Paleogeography, Paleoclimatology, Paleocology, v. 177, n. 1, p. 19-27, 2002.

BISHOP, P. Drainage rearrangement by river capture, beheading and diversion. Progress in Physical Geography, v. 19, n. 4, p. 449-473, 1995.

Stream profile change and longterm landscape evolution: early Miocene and modern rivers of the east Australian highland crest, central New South Wales, Australia. Journal of Geology, v. 93, p. 455-474, 1985.

BISHOP, P. et al. Knickpoint recession rate and catchment area: the case of uplifted rivers in eastern Scotland. Earth Surface Processes Landforms, v. 30, n. 6, p. 767-778, 2005.

BJÖRNBERG, A. J. S. Sedimentos pós-cretácicos do leste do estado de São Pau1o. Tese (Livre-Docência) - Escola de Engenharia de São Carlos, Universidade de São Paulo, São Carlos, 1965.

; LANDIM, P. M. B. Contribuição ao estudo da Formação Rio Claro (Neocenozoico).

Boletim Sociedade Brasileira de Geologia, São Paulo, v. 15, n. 4, p. 43-67, 1966.

CAETANO-CHANG, M. R.; WU, F.T. Arenitos flúvio-eólicos da porção superior da Formação Piramboia, na porção centro-leste paulista. Revista Brasileira de Geociências, v. 36, p. 296-304, 2006.

CAETANO-CHANG, M. R.; WU, F. T. Diagênese de arenitos da Formação Piramboia no centro-leste paulista. Geociências, São Paulo, v. 22, p. 33-39, 2003. Número especial.

CARPI JUNIOR, S. Técnicas cartográficas aplicadas à dinâmica da bacia do ribeirão Araquá - São Pedro (SP). Dissertação (Mestrado em Geografia) - Instituto de Geociências e Ciências Exatas, Universidade Estadual Paulista, Rio Claro, 1996.

COLTRINARI, L. Paleoambientes quaternários na América do Sul: primeira aproximação. In: CONGRESSO DA ASSOCIAÇÃO BRASILEIRA DE ESTUDOS DO QUATERNÁRIO, 3., 1991, Belo Horizonte. Anais... Belo Horizonte, 1991.

CORREAA, A. C. B.; FONSÊCA, F, N. Lineamentos de drenagem e de relevo como subsídio para a caracterização morfoestrutural e reativações neotectônicas da área da bacia do Rio Preto, Serra do Espinhaço Meridional-MG. Revista de Geografia, Recife: DCG-UFPE/NAPA, n. 1, 2010. Volume especial VIII Sinageo. 
COX, R. T. Analysis of drainage basin symmetry as a rapid technique to identify areas of possible Quaternary tilt-block tectonics: an example from the Mississippi Embayment. Geological Society of America Bulletin, v. 106, p. 571-581, 1994.

ETCHEBEHERE, M. L. C. Terraços neoquaternários no vale do Rio do Peixe, Planalto Ocidental Paulista: implicações estratigráficas e tectônicas. Tese (Doutorado em Geologia Regional) - Instituto de Geociências e Ciências Exatas, Universidade Estadual Paulista, Rio Claro-SP, 2000. v. I, v. II, mapas.

ETCHEBEHERE, M. L. C.; CASADO, F. C.; MORALES, N. Análise fluviomorfométrica do rio Corumbataí (SP): implicações tectônicas vinculadas à migração de nickpoint. $\mathbf{R e -}$ vista Geociências - UnG, v. 10, p. 74-94, 2011.

ETCHEBEHERE, M. L. C. et al. Aplicação do índice relação declividade-extensão - RDE na bacia do Rio do Peixe (SP) para detecção de deformações neotectônicas. Revista do Instituto de Geociências, São Paulo: USP, v. 4, n. 2, p. 43-56, 2004.

FACINCANI, E. M. Morfotectônica da depressão periférica paulista, cuesta basáltica e planalto interior: regiões de São Carlos, Rio Claro e Piracicaba-SP. Tese (Doutorado em Geociências e Geologia Regional) - Instituto de Geociências e Ciências Exatas, Universidade Estadual Paulista, Rio Claro-SP, 2000.

GUEDES, I. C. et al. Análise de perfis longitudinais de drenagens da bacia do rio Santo Anastácio (SP) para a detecção de possíveis deformações neotectônicas. Revista Geociências - UnG, v. 10, p. 77-104, 2006.

HACK, J. T. Stream profile analysis and stream gradient index. Journal Research of U. S. Geological Survey, v. 1, p. 421-429, 1973.

HARE, P. W.; GARDNER, I. W. Geomorphic indicators of vertical neotectonism along converging plate margins. Nicoya Península, Costa Rica. In: MORISAWA, M.; HACK, J. T. (Ed.). Tectonic Geomorphology: Procedings 15th. Annual Binghamton Geomorphology Simp. 1984.

HASUI, Y. Neotectônica e aspectos fundamentais da tectônica ressurgente no Brasil. In: SAADI, A. (Coord.). Boletim da Sociedade Brasileira de Geologia: $1{ }^{\circ}$ Workshop Neotectônica e Sedimentação Continental Cenozoica no Sudeste Brasileiro, 1990. p. 1-31. Disponível em: http://www.sbg-mg.org.br/site/mostra_boletim.php?id=18. Acesso em: 5 dez. 2016.

HOWARD, A. D. Drainage analysis in geologic interpretation: A summation. American Association of Petroleum Geologists Bullettin, v. 51, p. 2246-2259, 1967.

IBANEZ, D. M.; RICCOMINI, C. O uso da assimetria de bacias para o estudo neotectônico na Amazônia Central. In: SIMPÓSIO BRASILEIRO DE SENSORIAMENTO REMOTO-SBSR, 15., 2011, Curitiba-PR. Anais... Curitiba: Inpe, 2011. p. 3467-3474. 
LADEIRA, F. S. B.; SANTOS, M. O uso de paleossolos e perfis de alteração para a identificação e análise de superfícies geomórficas regionais: o caso da Serra de Itaqueri (SP).

Revista Brasileira de Geomorfologia, v. 6, p. 3-20, 2005.

LARUE, J. P. Tectonic influence on the Quaternary drainage evolution on the northwestern margin of the French Central Massif: the Cruese valley example. Geomorphology, n. 93, p. 398-420, 2008.

LICHTE, M. Arid processes in the SE Brazilian relief evolution during the last glacial. Boletim Instituto de Geociências da Universidade de São Paulo, São Paulo, v. 8, p. 201-211, 1991.

MASSOLI, M. Geologia da folha de Santa Rita do Passa Quatro. Revista do Instituto Geológico, São Paulo, v. 1, n. 1, p. 7-13, 1980.

MELO, M. S. A Formação Rio Claro e depósitos associados: sedimentação neocenozoica na Depressão Periférica Paulista. Tese (Doutorado em Geologia Sedimentar) - Instituto de Geociências, Universidade de São Paulo, São Paulo, 1995.

MURRAY, A. S.; WINTLE, A. G. Luminescence dating of quartz using an improved single-aliquot regenerative-dose protocol. Radiation Measurement, v. 32, p. 57-73, 2000.

OLIVEIRA, D. Estudo da origem dos materiais dos solos da cobertura arenosa do glacis de São Pedro, em São Pedro, SP. Monografia Individual (Trabalho de Graduação em Geografia Física) - Faculdade de Filosofia, Letras e Ciências Humanas, Universidade de São Paulo, São Paulo, 1992.

OLIVEIRA, D. B. et al. Elaboração de um mapa de lineamento estrutural e densidade de lineamento através de imagem SRTM em uma área ao norte do Rio Doce, ES. In: SIMPÓSIO BRASILEIRO DE SENSORIAMENTO REMOTO - SBSR, 14., 2009, Natal-RN. Anais... Natal: Inpe, p. 4157-4163, 2009.

OLIVEIRA, J. B.; JACOMINE, P. K. T.; CAMARGO, M. N. Classes gerais de solos do Brasil: guia auxiliar para o seu reconhecimento. Jaboticabal, SP: Fundunesp, 1992.

OPPENHEIM, V.; MALAMPHY, M. C. Sobre a tectônica da área de São Pedro-Xarqueada. Rio de Janeiro: Serviço de Fomento da Produção Mineral, 1936. (Avulso 7.)

ORTIZ-JAUREGUIZAR, E.; CLADERA, G. A. Paleoenvironmental evolution of southern South America during the Cenozoic. Journal of Arid Environmental, n. 66, p. 498-532, 2006.

PEIXOTO, C. A. B; THEODOROVICZ, A. Geodiversidade_SP. 2009. Disponível em:

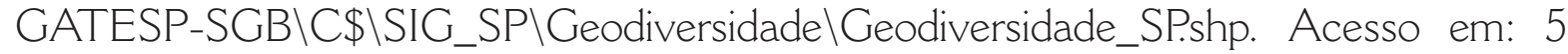
dez. 2016.

PENTEADO, M. M. Geomorfologia do setor centro-ocidental da Depressão Periférica Paulista. Tese (Doutorado em Geociências) - Faculdade de Filosofia, Ciências e Letras, Universidade Estadual Paulista, Rio Claro-SP, 1976. 
Implicações tectônicas na gênese das cuestas da bacia de Rio Claro (SP). Notícia Geomorfológica, Campinas, v. 8, n. 15, p. 19-41, 1968.

PERINOTTO, J. A. J. et al. Diques clásticos na Formação Corumbataí (P) no nordeste da bacia do Paraná, SP: análise sistemática e significações estratigráficas sedimentológicas e tectônicas. Geociências, v. 27, n. 4, p. 469-491, 2008.

PINHEIRO, M. R. Estudo morfotectônico da região da Serra de São Pedro e do Baixo Piracicaba-SP. Tese (Doutorado em Ciências) - Faculdade de Filosofia, Letras e Ciências Humanas, Universidade de São Paulo, São Paulo, 2014.

; QUEIROZ NETO, J. P. Neotectônica e evolução do relevo da região da Serra de São Pedro e do baixo Piracicaba / Sudeste do Brasil. Revista Brasileira de Geomorfologia, v. 16, p. 593-613, 2015.

Reflexões sobre a gênese da Depressão Periférica Paulista: o exemplo da região da Serra de São Pedro e do Baixo Piracicaba, SP. Revista do Instituto Geológico, São Paulo, v. 35, n. 1, p. 47-59, 2014.

RABASSA, J.; CLAPPERTON, C. M. Quaternary glaciations of the southern Andes. Quaternary Science Reviews, v. 9, n. 2/3, p. 153-174, 1990.

RICCOMINI, C. Considerações sobre a posição estratigráfica e tectonismo deformador da Formação Itaqueri na porção centro-leste do estado de São Paulo. Revista do Instituto Geológico, v. 18, p. 41-48, 1997.

; CRÓSTA, A. P. Análise preliminar de lineamentos em imagens de sensores remotos aplicada à prospecção mineral na área dos granitoides Mandira, SP. Boletim do Instituto de Geociências, São Paulo, v. 19, p. 23-37, 1988. (Série Científica.)

ROSSETTI, D. F. et al. Late Pleistocene-Holocene evolution of the Doce River delta, southeastern Brazil: Implications for the understanding of wave-influenced deltas. Marine Geology (Print), v. 367, p. 171-190, 2015.

SAADI, A. Neotectônica da Plataforma Brasileira: esboço e interpretação preliminares. Geonomus - Revista de Geociências, Belo Horizonte, v. 1, n. 6, p. 1-15, 1993.

SALAMUNI, E.; EBERT, H. D.; HASUI, Y. Morfotectônica da Bacia Sedimentar de Curitiba. Revista Brasileira de Geociências, v. 34, n. 4, p. 469-478, 2004.

SALLUN, A. E. et al. Datação absoluta de depósitos quaternários brasileiros por luminescência. Revista Brasileira de Geociências, v. 37, n. 2, p. 402-413, 2007.

SANTOS, M.; LADEIRA, F. S. B. Tectonismo em perfis de alteração da Serra de Itaqueri (SP): análise através de indicadores cinemáticos de falhas. Geociências, São Paulo, v. 25, p. 135-149, 2006.

SCHEEL-YBERT, R. Vegetation stability in the southeastern Brazilian coastal area from 5500 to $140014 \mathrm{C}$ yr BP deduced from charcoal analysis. Review of Palaeobotany and Palynology, n. 110, p. 111-138, 2000. 
SCHEEL-YBERT, R. et al. Holocene palaeoenvironmental evolution of the cerrado and semideciduous forest zone in the São Paulo State (Brazil), based on anthracology and soil d13C analysis. The Holocene (Sevenoaks), v. 13, n. 1, p. 73-81, 2003.

SCHERER, C. M. S. Análise estratigráfica e litológica da Formação Botucatu (Eocretáceo da Bacia do Paraná) no Rio Grande do Sul. Tese (Doutorado em Geociências) - Universidade Federal do Rio Grande do Sul, Porto Alegre, 1998.

SEEBER, L.; GORNITZ, V. River profiles along the Himalayan arc as indicators of active tectonics. Tectonophysics, v. 92, p. 335-367, 1983.

SOUSA, M. O. L. Evolução tectônica dos altos estruturais de Pitanga, Artemis, Pau d'Alho e Jiboia: centro do estado de São Paulo. Tese (Doutorado em Geologia Regional) - Instituto de Geociências e Ciências Exatas, Universidade Estadual Paulista, Rio Claro-SP, 2002.

STOCK, J. D.; MONTGOMERY, D. R. Geologic constraints on bedrock river incision using the stream power law. Journal of Geophysical Research - Solid Earth, v. 104, n. B3, p. 4983-4993, 1999.

THOMAS, M. Understanding the impacts of Late Quaternary climate change in tropical and sub-tropical regions. Geomorphology, n. 101, p. 146-158, 2008.

; THORP, M. B. Geomorphic response to rapid climatic and hydrologic change during the late Pleistocene and Early Holocene in the humid and sub-humid tropics. Quaternary Science Reviews, v. 14, p. 193-207, 1995.

ZANCOPÉ, M. H. C.; PEREZ FILHO, A. Anomalias no perfil longitudinal e migração dos meandros do rio Mogi Guaçu. Revista Brasileira de Geomorfologia, v. 10, p. 31 42, 2009. 